\title{
Explaining Ethnic Differences in Late Antenatal Care Entry by Predisposing, Enabling and Need Factors in the Netherlands. The Generation R Study
}

\author{
A. A. Choté - G. T. Koopmans • W. K. Redekop - C. J. M. de Groot • \\ R. J. Hoefman • V. W. V. Jaddoe • A. Hofman • E. A. P. Steegers • \\ J. P. Mackenbach $\cdot$ M. Trappenburg $\cdot$ M. Foets
}

Published online: 9 June 2010

(C) The Author(s) 2010. This article is published with open access at Springerlink.com

\begin{abstract}
Despite compulsory health insurance in Europe, ethnic differences in access to health care exist. The objective of this study is to investigate how ethnic differences between Dutch and non-Dutch women with respect to late entry into antenatal care provided by community midwifes can be explained by need, predisposing and enabling factors. Data were obtained from the Generation R Study. The Generation R Study is a multi-ethnic population-based prospective cohort study conducted in the city of Rotterdam. In total, 2,093 pregnant women with a Dutch, Moroccan, Turkish, Cape Verdean, Antillean, Surinamese Creole and Surinamese Hindustani background were included in this study. We examined whether ethnic differences in late antenatal care entry could be explained by need, predisposing and enabling factors. Subsequently, logistic regression analysis was used to assess the
\end{abstract}

A. A. Choté $(\bowtie) \cdot$ G. T. Koopmans · R. J. Hoefman ·

M. Trappenburg · M. Foets

Department of Health Policy and Management,

Erasmus University Rotterdam, PO Box 1738,

3000 DR Rotterdam, The Netherlands

e-mail: chote@bmg.eur.nl

A. A. Choté · V. W. V. Jaddoe

The Generation R Study Group,

Erasmus MC, Rotterdam, The Netherlands

W. K. Redekop

Institute for Medical Technology Assessment, Erasmus

University Rotterdam, Rotterdam, The Netherlands

C. J. M. de Groot

Department of Obstetrics and Gynaecology,

Erasmus MC, Rotterdam, The Netherlands

V. W. V. Jaddoe · A. Hofman

Department of Epidemiology,

Erasmus MC, Rotterdam, The Netherlands independent role of explanatory variables in the timing of antenatal care entry. The main outcome measure was late entry into antenatal care (gestational age at first visit after 14 weeks). With the exception of Surinamese-Hindustani women, the percentage of mothers entering antenatal care late was higher in all non-Dutch compared to Dutch mothers. We could explain differences between Turkish $(\mathrm{OR}=0.95$, CI: 0.57-1.58), Cape Verdean $(\mathrm{OR}=1.65$. CI: 0.96-2.82) and Dutch women. Other differences diminished but remained significant (Moroccan: OR = 1,74, CI: 1.07-2.85; Dutch Antillean OR 1.80, CI: 1.043.13). We found that non-Dutch mothers were more likely to enter antenatal care later than Dutch mothers. Because we are unable to explain fully the differences regarding Moroccan, Surinamese-Creole and Antillean women, future research should focus on differences between 1st and

V. W. V. Jaddoe

Department of Pediatrics,

Erasmus MC, Rotterdam, The Netherlands

E. A. P. Steegers

Department of Obstetrics and Gynaecology,

Erasmus MC, Rotterdam, The Netherlands

J. P. Mackenbach

Department of Public Health,

Erasmus MC, Rotterdam, The Netherlands

M. Trappenburg

Utrecht University, Utrecht, The Netherlands

C. J. M. de Groot

The Medical Centre, Hague, The Netherlands 
2nd generation migrants, as well as on language barriers that may hinder access to adequate information about the Dutch obstetric system.

Keywords Ethnicity $\cdot$ Antenatal care $\cdot$ Late entry

\section{Introduction}

Studies in developed countries point to a later entry into antenatal care and/or fewer visits by ethnic minorities in comparison to other groups [1-13]. Although scientific debate continues regarding the optimal number of visits, the necessity of timely entrance is unquestioned [14]. If women enter antenatal care too late, they cannot receive important timely health educational advices. Nor can they profit from the benefits of screening tests for the early detection and prevention of adverse pregnancy outcomes, which largely take place during the first trimester of pregnancy. Only a few studies have been carried out in Europe; but, despite universal insurance coverage in European countries, the studies that have been conducted nonetheless show similar results to studies conducted elsewhere. [4, 5].

Many of the larger cities in western European countries are facing a strong increase in migrant populations. In the Netherlands approximately $20 \%$ has a foreign background; in the large cities, nearly half of the population has a non-Dutch background. The largest groups are Turks, Moroccans, Surinamese and Dutch Antilleans. Turks and Moroccans came to the Netherlands as labor migrants during the 1960s and early 1970s. Suriname is a former colony that gained independence in 1975. During the period of decolonization, many Surinamese migrated to the Netherlands. The Dutch Antilles are still part of the Kingdom of the Netherlands and the availability and quality of educational institutions are important reasons for Dutch Antilleans to migrate to the Netherlands. In general, these groups are characterized by socioeconomic and language-related disadvantages [15].

Previous research has revealed that late entrance into antenatal care is associated with younger age $[2,8,16,17]$, low socio-economic position [16, 18-24], lack of insurance/ insurance status [16-18, 22, 25, 26], unmarried/single status [16, 17, 22, 25-27], smoking [2, 8], alcohol use [2], external barriers such as difficulty in getting an appointment [20], unintended/undesired/unplanned pregnancy [2, 16, 19, 20, $23,24,26,28,29]$ and multi-parity [8, 16, 17, 19, 25, 26]. Many studies explaining ethnic and racial differences in initiating antenatal care were conducted in the USA, and are to a large degree data-driven $[1-3,6,7,10,12]$. Andersen's model to study differences in health care use more systematically distinguishes between three groups of determinants: (1) need factors, (2) predisposing factors, reflecting the propensity to use services, and (3) enabling factors, reflecting opportunities to use services [30]. LaVeist assessed the role of a number of predisposing (marital status, age, educational attainment and income) and enabling factors (health insurance status, distance to antenatal care service) in differences between blacks and whites in timely antenatal care use [31]. He concluded that ethnic differences are not the consequence of predisposing factors, but could be attributed to a lack of enabling sources. He only included a limited number of predisposing variables and did not take need factors into consideration, identifying these as a constant, since all women were pregnant. However, in our opinion, need factors should be defined more broadly. For example, women experiencing poorer health very early in pregnancy may feel the need to seek antenatal care early.

Predisposing factors may still encompass divergent variables. Besides classical predisposing variables such as age, parity and concerns regarding the pregnancy, it is also interesting to determine whether late entry into antenatal care is associated with other health behaviors such as the use of tobacco or alcohol, and the use of folic acid. We hypothesize that women who are not likely to adopt healthy behavior regarding pregnancy will also not be inclined to enter antenatal care early in pregnancy.

Furthermore, because antenatal care is more universally accessible in Europe (including the Netherlands) than in the United States [32], we expect that predisposing and behavioral variables play a larger role than enabling factors. Financial barriers are largely absent, while midwifery practices are widely available. Dutch antenatal care is somewhat unique: community midwifery has a central role and only women with medical problems or a complicated obstetric history are referred to hospital-based obstetric care by a gynecologist [33]. Midwifery density is high in the Netherlands [34], whereby geographical access is also not an issue.

\section{Aim}

The aim of this study was to examine whether and to what extent ethnic differences between Dutch and several nonDutch groups in late entry into antenatal care by community midwives can be explained by need, predisposing and enabling factors.

\section{Methods}

\section{The Generation R Study}

Data for this study were obtained from the Generation $\mathrm{R}$ study. The Generation R study is a multi-ethnic populationbased prospective cohort study to investigate growth, 
development and health of urban children from fetal life until young adulthood, conducted in Rotterdam, the second largest city in the Netherlands. The Generation R Study has been described in detail elsewhere [35, 36]. In total 9,778 pregnant mothers with all ethnic backgrounds and with a delivery date between April 2002 and January 2006 were enrolled. Assessments during pregnancy included physical examinations, piloted questionnaires and fetal ultrasound examinations [36]. The questionnaires assessed a wide range of topics regarding health-related issues and lifestyle habits of the participants. The study was approved by the Medical Ethics Committee of the Erasmus Medical Centre, Rotterdam. Eligible women received written and oral information about the study and were asked for written informed consent.

\section{Study Population}

While the primary aim of the Generation R study focused on children, our aim focused on the pregnant mothers. For this particular analysis, only the women who entered antenatal care at a midwife practice, with an expected date of delivery between April 2002 and December 2004, were included. This is the only group for which all necessary data were available. Of these 3402 women, 308 were excluded, since they received only postnatal care by the participating midwives $(n=39)$, or were referred to the participating midwife practices by another health care provider $(n=269)$, because in these cases it was not possible to establish time of entry into antenatal care and their gestational age at first visit. Subsequently, 447 women were excluded because no information on their migrant background was available and
2 more women were excluded because information on gestational age or date of first visit could not be retrieved. If a woman had more than one pregnancy during the research period, only the first pregnancy was included.

The ethnic background of the participating pregnant women was based on the country of birth of the expecting mother and her parents, using the rules applied in current practice by Statistics Netherlands [37]. When at least one of the parents was born outside the Netherlands, the woman was classified as non-Dutch. If the pregnant woman was not born in the Netherlands, her ethnic background was determined based on her own country of birth. When the pregnant woman was born in the Netherlands, her ethnic background was determined by country of birth of her mother, unless this was also the Netherlands. If that was the case, ethnic background was established by country of birth of her father. When country of birth of both parents of the mother was the Netherlands, women were classified as native Dutch. All information about country of birth was obtained by questionnaire. In this study, we included the largest migrant groups in Rotterdam: native Dutch, Moroccan, Turkish, Dutch Antillean and Surinamese. Women with a Surinamese background are of mixed origin, mainly consisting of Hindustanis originating from India, and Creoles from Africa, and therefore differ in cultural background. For this reason, we further classified them as Surinamese-Hindustani and Surinamese-Creole, by asking the pregnant woman for her ethnic origin. Finally, we also included Cape Verdean migrants, because they constitute a large group in Rotterdam. Cape Verdeans migrated to the Netherlands from the 1960s onwards,
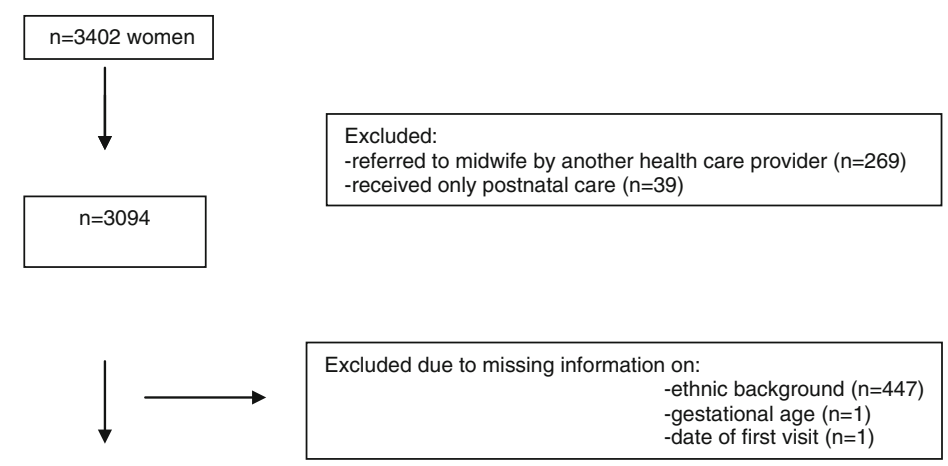

$\mathrm{n}=2645$

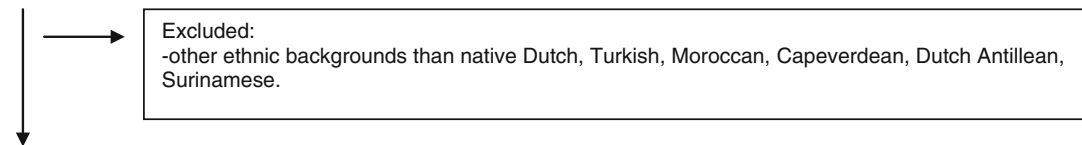

$\mathrm{n}=2093$ 
mostly for work-related reasons. Women with other migrant backgrounds were excluded because they belonged to too many different groups, resulting in excessively small numbers of women in each group available for study (total $N=552$ ).

The study population available for this analysis consisted of 2,093 women. The ethnic distribution in the study population differed only moderately from that of the population in the study area [36].

\section{Measurements}

Data were derived from the electronic antenatal charts (Micronatal ${ }^{\circledR}$ ) from 23 midwives at seven midwife practices that were participating in the Generation R Study, and from written questionnaires at enrolment in the study, which were available in native languages whenever necessary. Also, in case of illiteracy, assistance was available to fill out the questionnaire.

The outcome variable was delay in entry (yes/no) into antenatal care and was defined as whether or not the first visit took place after the gestational age of 14 weeks. Information about antenatal care and gestational age was derived from the electronic charts in which the midwives register their patient data. This criterion was based on the recommendations of the Dutch Society of Obstetrics and Gynecology [38].

Information on determinants was obtained from the participants through a questionnaire. As a need factor, we included self-perceived health during early pregnancy, consisting of five possible answers (excellent, very good, good, moderate, poor). Enabling factors included were: educational level of the mother and having a paid job (yes/ no). Educational level was assessed by recording the highest completed education, which was later reclassified into three categories: lower (primary school), intermediate (secondary school) and higher (higher education). Predisposing variables included age, household arrangement (married, cohabiting, no partner), parity (nulliparous/multiparous), and planned pregnancy (yes/no). Another predisposing variable that was included was the degree to which the pregnant woman was concerned and worried about the pregnancy. This variable consisted of a scale from 1 to 5 and was based on a set of 13 items (subquestions) about the confidence and worries of the women regarding their pregnancy, and each item was answered on a five point Likert scale ranging from almost never to almost always. The distribution of four items was highly skewed and these four items were therefore excluded. A principal component analysis was conducted on the remaining nine items and showed only one clear factor consisting of four items (Cronbach's alpha, 0.65). These four items refer to confidence in a favorable course of the pregnancy and confidence in the personal ability of the mother to adequately deal with the pregnancy. This variable ranged from little (1) to a lot of concern (4). Healthy behaviors regarding pregnancy were also considered as predisposing factors. We therefore included information on the use of folic acid (before pregnancy, as soon as pregnancy was known, later or never), smoking (never smoked, stopped smoking when pregnancy was known, still smoking during pregnancy) and alcohol use (never drinking, stopped drinking when pregnancy was known, still drinking during pregnancy).

\section{Analysis}

Descriptive analyses were performed on the outcome variable (late entry (yes/no)) and all determinants according to ethnic group. Differences were compared using $\chi^{2}$ in the case of categorical variables and analysis of variance in the case of continuous variables. Differences between the native Dutch and all non-Dutch were compared.

Logistic regression analyses were performed to determine the extent to which ethnic differences in late entry into antenatal care could be explained by need, enabling and predisposing factors. We first calculated unadjusted odds ratios, and then odds ratios adjusting separately for need, enabling and predisposing factors. Regarding the predisposing variables, we divided this group of variables into two categories; those referring to health-protective behavior and the remaining other variables. We distinguished between these two groups of predisposing factors, because those reflecting health-protective behavior have rarely been included in research. Finally, a full model was applied, adjusting simultaneously for the four groups of explanatory variables.

Subsequently, we used the full logistic regression model to determine the degree of association that each factorincluding ethnic background-had with the chance of late antenatal care use.

We used separate categories for the missing data on the categorical explanatory variables.

The statistical analyses were performed using SPSS version 15.0 for Windows (SPSS Inc, Chicago, Illinois, USA).

\section{Results}

Figure 1 presents the distribution of gestational age at entry into antenatal care according to the ethnic background of the mother. This figure illustrates that the percentage of Dutch women entering antenatal care early is higher than any other ethnic group. 


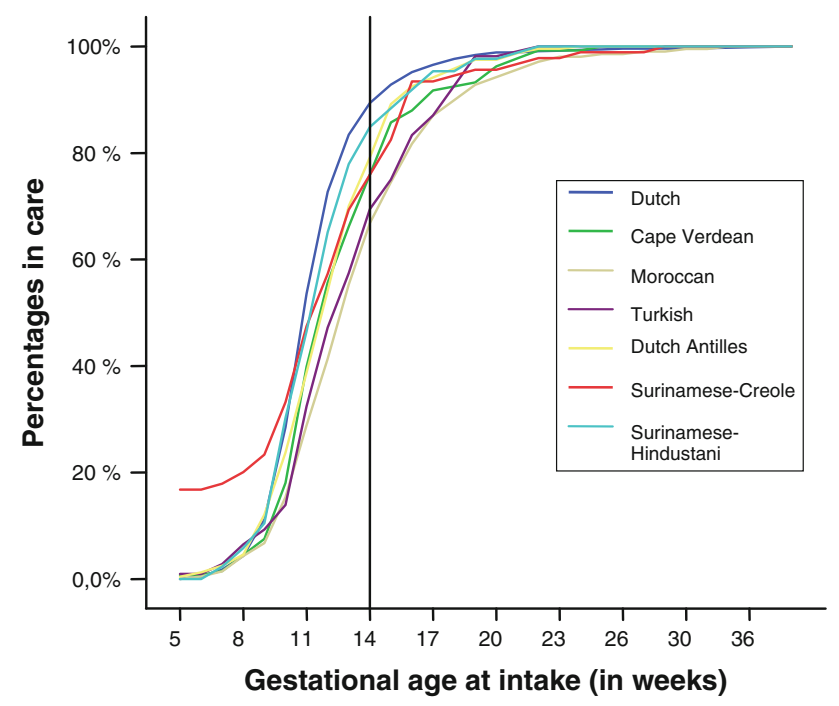

Fig. 1 Gestational age at intake according to ethnic background

Table 1 shows the characteristics of the study population according to ethnic background. Among all non-Dutch groups, the percentages entering antenatal care after 14 weeks of pregnancy was higher than among Dutch mothers. Compared to Dutch mothers, the percentages of women who considered their health as excellent or very good were considerably lower among the non-Dutch mothers. Compared to Dutch women, the mean maternal age of women of non-Dutch origin was lower. Additionally, non-Dutch mothers had lower education levels, were more likely not to have a paid job, and were more often multiparous than Dutch mothers. In comparison to the Dutch, Moroccan and Turkish mothers were more often married; while single mothers were predominant in the Cape Verdean, Antillean and especially in the Surinamese Creole mothers. Compared to Dutch women, the frequencies of non-Dutch women taking folic acid before pregnancy were lower. Also the frequency of mothers who started taking folic acid once they knew they were pregnant was lower in non-Dutch mothers, except among both Surinamese groups. Moroccan women seldom smoke; the percentages for smoking cessation during pregnancy were highest in Dutch and Surinamese-Creole mothers. Turkish women most frequently smoke and less frequently quit smoking during pregnancy. In all non-Dutch groups, the percentage of women refraining from alcohol use was higher than among the Dutch mothers.

Table 2 displays the logistic regression models for investigating the degree to which ethnic differences in antenatal care could be explained by different types of variables. The unadjusted model showed large ethnic differences, which were more pronounced in Moroccan mothers, followed by the Dutch Antillean and the Surinamese-Creole. Surinamese-Hindustani did not differ from the Dutch reference group. Adjustment for perceived health at the beginning of the pregnancy (model 2) did not reduce ethnic differences. After adjustment for the enabling variables (model 3) the ethnic differences decreased but remained significant, except in the Turkish women. Adjustment for the classical predisposing variables reduced differences between all migrant groups and the Dutch (model 4), although these variables nevertheless remained significant. Adjustment for behavioral variables (model 5) also reduced ethnic differences: especially differences between Dutch, Turkish and Moroccan women became smaller, but remained significant. The degree of ethnic differences decreased after adjustment for all variables simultaneously (model 6, full model) especially in Turkish and Cape Verdean women, where the differences with Dutch women were no longer significant.

Table 3 shows the role of each independent predictor of model 6 on late entry, after adjustment for the other independent variables. Ethnic background was associated with late entry, independent of the other explanatory variables, except in Turkish, Cape Verdean and SurinameseHindustani women. Lack of a paid job was associated with late entry into antenatal care, as was a low or intermediate education (compared to a higher education). Late entry was not associated with perceived health of the mother, age, parity, martial status, nor degree of worry about the pregnancy. However, the behavioral factors were strongly associated with late entry. Odds ratios were significantly higher in women never using folic acid, as compared to those that already used it before getting pregnant. While women who started using folic acid later in pregnancy were more likely to receive late antenatal care, the chance was not significantly greater than the chance seen among women using folic acid before pregnancy. Women who stopped smoking during pregnancy were significantly less likely to receive late antenatal care than those who never smoked. The probability of late antenatal care among those who continued smoking during pregnancy did not differ from that seen among the never smokers. Very similar findings were observed for alcohol users: the women who stopped during pregnancy were the ones least likely to receive late antenatal care.

\section{Discussion and Conclusions}

In this study we found that the percentages of mothers entering antenatal care late was higher in non-Dutch than in Dutch mothers, with the exception of SurinameseHindustani. These percentages were especially high among Moroccan and Antillean mothers. As a consequence, mothers with a non-Dutch background are less likely to 
Table 1 Characteristics of the study population

\begin{tabular}{|c|c|c|c|c|c|c|c|c|}
\hline$N$ & $\begin{array}{l}\text { Dutch } \\
1,242\end{array}$ & $\begin{array}{l}\text { Moroccan } \\
208\end{array}$ & $\begin{array}{l}\text { Turkish } \\
240\end{array}$ & $\begin{array}{l}\text { Cape } \\
\text { Verdean } \\
133\end{array}$ & $\begin{array}{l}\text { Dutch } \\
\text { Antilleans } \\
108\end{array}$ & $\begin{array}{l}\text { Suriname } \\
\text { Creoles } \\
76\end{array}$ & $\begin{array}{l}\text { Suriname } \\
\text { Hindustani } \\
86\end{array}$ & $P$-value \\
\hline Late antenatal care entry $(\%)$ & 10.6 & 33.2 & 20.8 & 24.1 & 30.6 & 28.9 & 15.1 & $P<0.001$ \\
\hline Age in years (mean-sd) & $31.1(4.6)$ & $27.7(4.9)$ & $25.7(4.4)$ & $26.7(5.7)$ & $25.7(4.7)$ & $26.9(6.1)$ & $26.4(4.9)$ & $P<0.001$ \\
\hline Perceived health status (\%) & & & & & & & & $P<0.001$ \\
\hline Excellent & 13.1 & 6.7 & 4.6 & 12.8 & 10.2 & 5.3 & 5.8 & \\
\hline Very good & 37.8 & 18.8 & 10.3 & 17.3 & 19.4 & 25.0 & 23.3 & \\
\hline Good & 42.1 & 54.3 & 63.8 & 51.9 & 57.4 & 51.3 & 52.3 & \\
\hline Moderate & 3.1 & 13.9 & 12.1 & 10.5 & 8.3 & 9.2 & 14 & \\
\hline Poor & 0.2 & 1.0 & 0.4 & 0.8 & 0 & 0 & 1.2 & \\
\hline Missing & 3.8 & 5.3 & 2.9 & 6.8 & 4.6 & 9.2 & 3.5 & \\
\hline Paid job (\%) & & & & & & & & $P<0.001$ \\
\hline Yes & 72.4 & 19.2 & 28.3 & 42.9 & 19.4 & 39.5 & 30.2 & \\
\hline No & 12.8 & 31.7 & 39.6 & 21.8 & 50.9 & 23.7 & 40.7 & \\
\hline Missing & 14.8 & 49.0 & 32.1 & 35.3 & 29.6 & 36.8 & 29.1 & \\
\hline Educational level (\%) & & & & & & & & $P<0.001$ \\
\hline Lower & 3.6 & 24.0 & 27.1 & 22.6 & 13.9 & 14.5 & 12.8 & \\
\hline Intermediate & 35.4 & 55.8 & 55.4 & 63.2 & 71.3 & 64.5 & 73.3 & \\
\hline Higher & 60.1 & 12.0 & 12.1 & 9.0 & 12.0 & 15.8 & 10.5 & \\
\hline Missing & 0.8 & 8.2 & 5.4 & 5.3 & 2.8 & 5.3 & 3.5 & \\
\hline Household arrangement (\%) & & & & & & & & $P<0.001$ \\
\hline Married & 42.8 & 93.3 & 83.8 & 12.0 & 15.7 & 10.5 & 34.9 & \\
\hline Cohabiting & 47.7 & 2.4 & 6.3 & 32.3 & 29.6 & 31.6 & 38.4 & \\
\hline No partner & 8.6 & 1.4 & 5.8 & 51.1 & 52.8 & 57.9 & 22.1 & \\
\hline Missing & 0.8 & 2.9 & 4.2 & 4.5 & 1.9 & 0 & 4.7 & \\
\hline Parity $(\%)$ & & & & & & & & $P<0.001$ \\
\hline 0 & 58.7 & 34.1 & 53.3 & 61.7 & 60.2 & 57.9 & 59.3 & \\
\hline$\geq 1$ & 41.1 & 65.9 & 46.7 & 36.8 & 38.9 & 40.8 & 40.7 & \\
\hline Missing & 0.2 & 0 & 0 & 1.5 & 0.9 & 1.3 & 0 & \\
\hline Planned pregnancy $(\%)$ & & & & & & & & $P<0.001$ \\
\hline Yes & 74.8 & 60.6 & 55.8 & 37.6 & 30.6 & 40.8 & 44.2 & \\
\hline No & 21.4 & 32.2 & 37.9 & 52.6 & 62.0 & 55.3 & 52.3 & \\
\hline Missing & 3.8 & 7.2 & 6.3 & 9.8 & 7.4 & 3.9 & 3.5 & \\
\hline $\begin{array}{l}\text { Pregnancy concern (mean- } \\
\text { sd) }\end{array}$ & $2.1(0.6)$ & $2.5(0.7)$ & $2.6(0.6)$ & $2.3(0.7)$ & $2.3(0.7)$ & $2.3(0.7)$ & $2.5(0.6)$ & $P<0.001$ \\
\hline Folic acid use $(\%)$ & & & & & & & & $P<0.001$ \\
\hline Before pregnancy & 44.4 & 13.0 & 14.2 & 18.0 & 21.3 & 9.2 & 15.1 & \\
\hline $\begin{array}{l}\text { When woman first knew } \\
\text { about } \\
\text { pregnancy }\end{array}$ & 37.3 & 16.3 & 24.2 & 24.1 & 21.3 & 42.1 & 39.5 & \\
\hline Later in pregnancy & 3.2 & 3.4 & 3.3 & 3.8 & 11.1 & 9.2 & 5.8 & \\
\hline Not & 13.3 & 63.5 & 52.5 & 49.6 & 43.5 & 36.8 & 38.4 & \\
\hline Missing & 1.8 & 3.8 & 5.8 & 4.5 & 2.8 & 2.6 & 1.2 & \\
\hline Maternal smoking (\%) & & & & & & & & $P<0.001$ \\
\hline Never & 49.9 & 91.8 & 48.3 & 61.7 & 63.0 & 53.9 & 62.8 & \\
\hline Stopped during pregnancy & 32.9 & 1.9 & 18.3 & 27.1 & 21.3 & 34.2 & 19.8 & \\
\hline $\begin{array}{l}\text { Continued during } \\
\text { pregnancy }\end{array}$ & 15.9 & 4.3 & 32.9 & 10.5 & 13.9 & 10.5 & 16.3 & \\
\hline Missing & 1.2 & 1.9 & 0.4 & 0.8 & 1.9 & 1.3 & 1.2 & \\
\hline
\end{tabular}


Table 1 continued

\begin{tabular}{|c|c|c|c|c|c|c|c|c|}
\hline$N$ & $\begin{array}{l}\text { Dutch } \\
1,242\end{array}$ & $\begin{array}{l}\text { Moroccan } \\
208\end{array}$ & $\begin{array}{l}\text { Turkish } \\
240\end{array}$ & $\begin{array}{l}\text { Cape } \\
\text { Verdean } \\
133\end{array}$ & $\begin{array}{l}\text { Dutch } \\
\text { Antilleans } \\
108\end{array}$ & $\begin{array}{l}\text { Suriname } \\
\text { Creoles } \\
76\end{array}$ & $\begin{array}{l}\text { Suriname } \\
\text { Hindustani } \\
86\end{array}$ & $P$-value \\
\hline Maternal alcohol use (\%) & & & & & & & & $P<0.001$ \\
\hline Never & 35.3 & 97.1 & 94.6 & 54.9 & 67.6 & 60.5 & 81.4 & \\
\hline Stopped during pregnancy & 36.2 & 1.0 & 2.1 & 36.8 & 23.1 & 27.6 & 14.0 & \\
\hline Continued in pregnancy & 27.2 & 0 & 1.7 & 6.8 & 7.4 & 9.2 & 3.5 & \\
\hline Missing & 1.4 & 1.9 & 1.7 & 1.5 & 1.9 & 2.6 & 1.2 & \\
\hline
\end{tabular}

receive timely health educational advice or benefit from screening opportunities.

Additionally, we found that these ethnic differences diminished, but remained significant, in three of the six ethnic groups after taking into account many factors that can influence the entry into antenatal care. However, the differences between Turkish and Cape Verdean women versus the Dutch women could be fully explained by the explanatory variables included in the analysis. Differences in design notwithstanding, differences between Turkish and Dutch women also disappeared in the multivariate analysis in the study by Alderliesten [9]. The initially large difference between the Moroccan group and the Dutch group remained statistically significant in our study but nevertheless diminished considerably. In this study we focused on the explanation of ethnic differences in the timing of entry into antenatal care, and not of ethnic differences in the number of contacts, because the latter did not occur in our study population.

A probable explanation for the difference between Dutch women and two non-Dutch groups (Moroccan and Turkish women) could be found in the behavioral factors. For example, women who adapt their behavior positively early in pregnancy-by abstaining from alcohol and tobacco use-entered antenatal care earlier than those already behaving healthy before the pregnancy. However, the observed differences between Dutch women and two non-Dutch groups (Turks and Moroccans) appeared to a large extent to exist because of the behavioral adaptation of the Dutch women. Neither Turkish nor Moroccan women usually drink alcohol, which is related to their religion, as most of them are Islamic. In addition, few Moroccan women smoke, unlike Turkish women, who were more likely to smoke than women in other groups, also during pregnancy. Furthermore, the causal sequence is questionable, as it could be the case that these women adapted their behavior after they were advised to do so by the midwives during early pregnancy. Unfortunately, we do not know whether the behavioral adaptation during pregnancy took place as a response to such advice. If it did, our hypothesis-that women who are not directed towards healthy behavior regarding pregnancy will also not be inclined to enter antenatal care early in pregnancy-cannot be confirmed. Further examination of this point is necessary.

Regarding folic acid use, women who never used it during pregnancy entered antenatal care late. A similar trend (not significant) was visible for those who used it late in pregnancy, compared to women who used it either before pregnancy or as soon as they knew that they were pregnant. These results suggest an underlying adverse behavioral pattern including both late entry and adverse health behavior. Because this seems to be at least partly the case, health education cannot be left only to the midwives. The continuation of smoking during pregnancy by Turkish mothers also points in that direction.

Although we expected that poorer perceived health would prompt early antenatal care use, our study did not confirm this; nor did it explain differences in antenatal care entry between Dutch and non-Dutch women. Adjustment for more objective risk factors (e.g.: the presence of chronic conditions, such as diabetes, and complications in previous pregnancies) could only have been partly useful, because especially multiparae women then directly enter secondary care. However, future research should take into account more specific subjective health assessments directly related to pregnancy that could affect time of entry (e.g.: nausea and vomiting).

Enabling factors explained part of the differences between Dutch and non-Dutch women, but not the majority-except in Turkish women. We only included educational level and not other indicators of socio-economic position, such as occupational level and income level. We decided to focus on education because it reflects the more general concept of enabling factors better than other indicators. Indeed, educational level reflects not only financial resources, which are less relevant in a system without financial barriers, but also general health knowledge and health literacy. It should be mentioned that there is no consensus on whether having a paid job and educational level should be considered as either enabling or as predisposing factors. We decided to consider them as enabling factors, because they facilitate access to information. In 


\begin{tabular}{|c|c|c|c|c|c|c|c|c|}
\hline \multirow{3}{*}{ 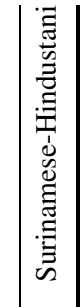 } & \multirow{3}{*}{ 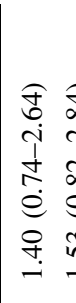 } & \multirow{3}{*}{ 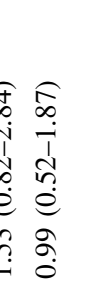 } & \multirow{3}{*}{$\begin{array}{l}\hat{\sigma} \\
\stackrel{i}{1} \\
\frac{1}{n} \\
e \\
0 \\
0 \\
=\end{array}$} & \multirow{3}{*}{$\begin{array}{l}0 \\
o \\
i \\
i \\
n \\
n \\
e \\
\infty \\
\infty \\
0 \\
-\end{array}$} & \multirow{3}{*}{$\begin{array}{l}\widehat{o} \\
n \\
\mathfrak{1} \\
\infty \\
n \\
0 \\
0 \\
n \\
\mathfrak{0} \\
0\end{array}$} & \multicolumn{3}{|c|}{$\begin{array}{l}\text { Table } 3 \text { Association between independent variables and late entry } \\
\text { into antenatal care, adjusted for the influence of the other independent } \\
\text { variables, as assessed by logistic regression analysis (odds ratios and } \\
95 \% \text { confidence intervals) }\end{array}$} \\
\hline & & & & & & $*=$ Reference group & $\begin{array}{l}\text { Odds } \\
\text { ratio }\end{array}$ & 95\% C.I. \\
\hline & & & & & & Ethnicity mother & & \\
\hline 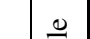 & & & & & & Dutch* & 1 & \\
\hline 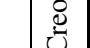 & $\widehat{\sigma} \sqrt{5}$ & $\widehat{\infty}$ & ले & $\widehat{\infty}$ & $\stackrel{\infty}{\sim}$ & Turkish & 0.95 & $0.57-1.58$ \\
\hline $\begin{array}{l}1 \\
\vdots \\
0\end{array}$ & & $\dot{i}$ & $\dot{I}$ & $\dot{I}$ & $\dot{1}$ & Moroccan & 1.74 & $1.07-2.87$ \\
\hline$\Xi$ & & i & ?े & $\stackrel{n}{n}$ & $=$ & Surinamese-Hindustani & 0.75 & $0.38-1.50$ \\
\hline 寻 & 105 & 10 & ? & $\infty$ & $\mathbf{I}$ & Surinamese-Creoles & 2.04 & $1.10-3.78$ \\
\hline & $\dot{m}$ & $i$ & $\vec{i}$ & $i$ & $i$ & Cape Verdean & 1.65 & $0.96-2.82$ \\
\hline & $\hat{\circ} \vartheta$ & $\hat{\sigma} \widehat{\sigma}$ & $\widehat{\theta}$ & $\widehat{\infty}$ & m & Dutch Antilles & 1.80 & $1.04-3.13$ \\
\hline$\stackrel{\varrho}{=}$ & in & $\ddot{0}$ & $\stackrel{\text { ণ }}{+}$ & $\stackrel{+}{\sim}$ & $\dot{m}$ & Perceived health & & \\
\hline 坖 & $\stackrel{\substack{1 \\
+}}{\infty}$ & $\begin{array}{ll}1 \\
7 \\
0\end{array}$ & $n$ & to & t & Excellent* & 1 & \\
\hline త్ర & $\begin{array}{c}-1 \\
0\end{array}$ & $i_{0}^{i}=$ & $\Xi$ & 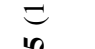 & $\Xi$ & Very good & 1.39 & $0.87-2.22$ \\
\hline $\bar{\Xi}$ & & $\dot{i}$ & in & 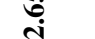 & $\stackrel{\infty}{\infty}$ & Good & 0.91 & $0.58-1.44$ \\
\hline & & & & & & Moderate/poor & 1.28 & $0.70-2.31$ \\
\hline$\exists$ & ले ఫ & $\begin{array}{l}\infty \\
+\infty \\
\infty\end{array}$ & ๙े & $\sqrt{n}$ & స్ & Missing & 0.86 & $0.36-2.04$ \\
\hline 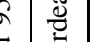 & & $i d$ & $\hat{n}$ & $\frac{1}{4}$ & กิ & Educational level & & \\
\hline$>$ & 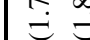 & $\stackrel{0}{\stackrel{0}{0}}$ & $\stackrel{\overbrace{}}{=}$ & $\stackrel{\overbrace{}}{=}$ & $\stackrel{\rho}{e}$ & Higher* & 1 & \\
\hline ڤ్ర & $\approx \infty$ & రై & ๕̊ & $\hat{a}$ & 6 & Lower & 2.10 & $1.27-3.33$ \\
\hline & i c & j & i & - & - & Intermediate & 1.48 & $1.03-2.11$ \\
\hline & $\widehat{\equiv}$ & $\widehat{1}$ & $\widehat{f}$ & $\overparen{m}$ & $\widehat{\infty}$ & Missing & 1.59 & $0.70-3.58$ \\
\hline & & $i$ & ก & i & $?$ & Having a paid job & & \\
\hline & J & $\sigma$ & ?o & ¿ & in & Yes* & 1 & \\
\hline$\frac{n}{2}$ & $=0$ & $\underbrace{}_{0}=$ & $\underset{n}{=}$ & $=$ & $\underbrace{e}_{n}$ & No & 1.65 & $1.18-2.32$ \\
\hline 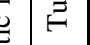 & & ? & 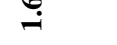 & & 0 & Missing & 1.31 & $0.94-1.84$ \\
\hline & $\widehat{\partial} \approx$ & $\approx$ & 2 & 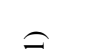 & శิ & Age & 0.99 & $0.96-1.02$ \\
\hline & & $\infty$ & in & $\stackrel{\vec{b}}{\dot{n}}$ & $\infty$ & Parity & & \\
\hline$\approx$ & $2 \frac{1}{2}$ & $\frac{1}{1}$ & $\frac{1}{2}$ & & $\frac{1}{6}$ & Nulliparous* & 1 & \\
\hline$\ddot{0}$ & i c & $i$ & d & & 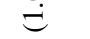 & Multiparous & 1.18 & $0.89-1.58$ \\
\hline 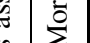 & $\stackrel{0}{=}$ & 5 & లి & m? & $\mathbb{7}$ & Household arrangement & & \\
\hline & & & & & & Married* & 1 & \\
\hline & & $\dot{D}$ & & & & Cohabiting & 0.83 & $0.58-1.17$ \\
\hline & & $\underline{0}$ & & & & No partner & 1.06 & $0.68-1.64$ \\
\hline & & $\tilde{\Xi}$ & & & & Missing & 0.61 & $0.22-1.69$ \\
\hline & 4 & 5 & & 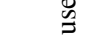 & สే & Planned pregnancy & & \\
\hline & & 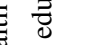 & $\ddot{\otimes} \ddot{g}$ & $\ddot{i} \bar{O}$ & పే & Yes* & 1 & \\
\hline & & $\ddot{g}$ & 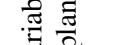 & .ేี $\frac{0}{\pi}$ & $\pi$ & No & 1.27 & $0.94-1.70$ \\
\hline & & . त्ञै & $E$ & 疋 oî & 0 & Missing & 0.58 & $0.26-1.30$ \\
\hline & & $\sum^{\pi}$ & $\Xi \mathscr{\Xi}$ & $\bar{T} \frac{\pi}{3}$ & $\cong$ & Pregnancy concern & 0.93 & $0.77-1.13$ \\
\hline & & 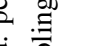 & 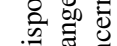 & పี हี & की & Folic acid use & & \\
\hline & & 记 & 氙 & 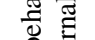 & Dृ & Before pregnancy* & 1 & \\
\hline & -3 & 5 & 흥 & t) & क & As soon as woman knew about pregnancy & 1.04 & $0.72-1.51$ \\
\hline & $\stackrel{0}{2}$ & 웅 & రृ & 8 & $\widetilde{D}$ & Later & 1.74 & $0.93-3.26$ \\
\hline & 艼 & $\stackrel{\bar{g}}{\Xi}$ & $\stackrel{\Xi}{\Xi}$ &. $\bar{\Xi}$ &. $\bar{\Xi}$ & No & 1.89 & $1.30-2.74$ \\
\hline & 5 & $\frac{2}{2}$ & 安离 & 这 & $\sum_{00}^{\pi}$ & Missing & 1.21 & $0.45-3.21$ \\
\hline
\end{tabular}


Table 3 continued

\begin{tabular}{llc}
\hline$*$ Reference group & $\begin{array}{l}\text { Odds } \\
\text { ratio }\end{array}$ & $95 \%$ C.I. \\
\hline Smoking & & \\
Never* & 1 & \\
Stopped & $\mathbf{0 . 6 7}$ & $0.48-0.94$ \\
Continued & 0.94 & $0.65-1.35$ \\
Missing & 0.08 & $0.01-1.31$ \\
Alcohol use & & \\
Never* & 1 & \\
Stopped & $\mathbf{0 . 6 4}$ & $0.44-0.92$ \\
Continued & 1.35 & $0.90-2.02$ \\
Missing & 2.48 & $0.37-$ \\
& & 16.67 \\
\hline
\end{tabular}

Significant odds ratios $(P<0.05)$ in bold

this respect, we acknowledge one of the limitations of this study. Although ethnic minorities without a legal status are nevertheless formally entitled to antenatal care, in practice it is unlikely that many of them were included in the Generation $\mathrm{R}$ study, because they would be afraid of recognition by official authorities.

The classical predisposing variables were not significantly associated with early/late entry into antenatal care. This is in contradiction with most previous studies. Nevertheless, in our study the associations between parity and time of entry, and between planned character of the pregnancy and time of entry, were as expected but without being significant. It is important to note that we assessed the influence of these factors after adjustment for all other explanatory variables, whereas most previous studies took into account fewer explanatory variables. Indeed, our inclusion of more explanatory variables than most previous studies represents an important strength of this study over previous studies. Nevertheless, we could not include a number of attitudinal characteristics such as the degree to which women recognize the importance of early antenatal care. It might be possible that migrant women value antenatal care less than Dutch women. This might be the consequence of lack of familiarity with antenatal care in the country of origin, but also with lack of access to information due to problems with understanding the Dutch language. It could therefore be interesting to investigate differences in timing of entry between non-Dutch women born outside the Netherlands (1st generation) and those born in the Netherlands (2nd generation).

An advantage of our study was the possibility to distinguish between Surinamese-Creole and SurinameseHindustani women, two distinctly different groups that have different origins, one with an African background, and the other with an Asian background. Our study found large differences in delay in antenatal care use between these two groups: Surinamese-Hindustani did not differ significantly from Dutch women, but Surinamese-Creoles did.

Our results should be interpreted with some caution because of some limitations in our study. Besides the ones already mentioned above, one should also acknowledge the following. First, we did not include all midwife practices participating in the larger Generation R study. We excluded three midwife practices, since they did not use electronic antenatal charts. There was no indication that the ethnic composition of these practices was different from the participating practices (analyses not shown). Secondly, we excluded mothers from the analysis whose ethnic background was unknown. We analyzed whether the timing of their entry into antenatal care was different from the women included in this study, and found that this was not the case (analyses not shown). Thirdly, we defined late antenatal care entry as entry after 14 weeks of pregnancy. This was based on the recommendations for basic antenatal care developed by the Dutch Society of Obstetrics and Gynecology (NVOG) at the time of the data collection. The recommendations by the NVOG are based more on professional agreement than on scientific evidence, and currently it is often advised to seek antenatal care earlier in pregnancy, and even before pregnancy [39, 40]. Finally, it is likely that migrant groups with a higher socio-economic position were overrepresented in the Generation R Study, as enrolment of migrant women was more difficult due to language and cultural barriers. Since a higher socio-economic position is associated with earlier entry into antenatal care, it is probable that the ethnic differences found in this study represent an underestimation of true differences.

In conclusion, although we could explain part of the ethnic differences in the timing of entry into antenatal care, differences between Dutch women and women in some migrant groups remained statistically significant. One possible explanation might be that migrant women are not well informed about how obstetric care is organized in the Netherlands and that this lack of knowledge leads to delay in antenatal care entry. In particular, the role of midwives may be unknown, and women might prefer to consult their general practitioner early in pregnancy. However, at least in Rotterdam (where this study took place), a visit to the general practitioner is not likely to be the first step in antenatal care, since women are advised to consult a midwife first. We did not examine differences in generational status (1st and 2nd generation migrants) and language factors as indicators of cultural distance, as our main aim was to explain differences between non-Dutch and Dutch women. Generational status is not applicable for the Dutch group. As far as knowledge of Dutch among Dutch women was concerned, we assumed that their mastery of Dutch was optimal, and it was therefore not assessed in the questionnaire. Because we are unable to explain all of the 
differences between the native Dutch and a number of nonDutch groups, it would be worth investigating whether mastery of Dutch language plays a role, also because health literacy is considered as an important barrier to adequate health care use [41]. In the Netherlands some migrants are rather fluent in Dutch (Surinamese), while others are less so (especially Turks and Moroccans). Therefore, lack of good Dutch mastery cannot explain all of the remaining differences, especially not in Surinamese-Creole and Antillean women. Future research should assess differences within migrant groups by investigating differences by generational status and mastery of Dutch language.

The results of this study are also relevant for clinicians. Midwives need to inform women of the importance of timely booking for antenatal care especially when they booked late during a previous pregnancy. This is all the more important, given that a previous study demonstrated that the difference between Dutch and non-Dutch women in timely entry was greater among multiparae than among primiparae [42].

Acknowledgments We gratefully acknowledge the contribution of all women participating in the Generation R study and the midwives in Rotterdam, who provided data for this study. We thank Samantha Adams for editing our manuscript regarding English language. The first phase of the Generation R Study was made possible by financial support from the Erasmus Medical Centre, Rotterdam, the Erasmus University Rotterdam and the Netherlands Organization for Health Research and Development (ZonMw). The department of Health Policy and Management received an additional grant, specifically for the study presented in this article, from the Netherlands Organization for Scientific Research (NWO), in collaboration with the Netherlands Organization for Health Research and Development (ZonMw) (Grant No. 261-98-911). Supplementary financing was received from the Department of Health Policy and Management to accomplish this study, whereas Generation $\mathrm{R}$ provided the housing and computer facilities.

\section{Disclosure None.}

Details of Ethics Approval The Generation R Study was approved by the Medical Ethical Committee of the Erasmus Medical Centre, Rotterdam. Number of approval: 198.782/2001/31.

Open Access This article is distributed under the terms of the Creative Commons Attribution Noncommercial License which permits any noncommercial use, distribution, and reproduction in any medium, provided the original author(s) and source are credited.

\section{References}

1. Conrad, J. K., Hollenbach, K. A., Fullerton, J. T., \& Feigelson, H. S. (1998). Use of prenatal services by hispanic women in San Diego County: A comparison of urban and rural settings. Journal of Nurse-Midwifery, 43(2), 90-96.

2. Pagnini, D., \& Reichman, N. E. (2000). Psychosocial factors and the timing of prenatal care among women in New Jersey's HealthStart program. Family Planning Perspectives, 32(2), 56-64.
3. Frisbie, W. P., Echevarria, S., \& Hummer, R. A. (2001). Prenatal care utilization among non-Hispanic whites, African Americans, and Mexican Americans. Maternal and Child Health Journal, 5(1), 21-33.

4. Kupek, E., Petrou, S., Vause, S., \& Maresh, M. (2002). Clinical, provider and sociodemographic predictors of late initiation of antenatal care in England and Wales. BJOG, 109, 265-273.

5. Rowe, R. E., \& Garcia, J. (2003). Social class, ethnicity and attendances for antenatal care in the United Kingdom: A systematic review. Journal of Public Health Medicine, 25(2), 113119.

6. Johnson, A. A., El-Khorazaty, M. N., Hatcher, B. J., Wingrove, B. K., Milligan, R., Harris, C., et al. (2003). Determinants of late prenatal care initiation by African American women in Washington, DC. Maternal and Child Health Journal, 7, 103-114.

7. Gavin, N. I., Adams, E. K., Hartmann, K. E., Benedict, M. B., \& Chireau, M. (2004). Racial and ethnic disparities in the use of pregnancy-related health care among Medicaid pregnant women. Maternal and Child Health Journal, 8(3), 113-126.

8. Trinh L. T., \& Rubin G. (2006). Late entry to antenatal care in New South Wales, Australia. Reproductive Health 18(3):8. doi: 10.1186/1742-4755-3-8.

9. Alderliesten, M. E., Vrijkotte, T. G. M., van der Waal, M. F., \& Bonsel, G. J. (2007). Late start of antenatal care among ethnic minorities in a large cohort of pregnant women. BJOG, 114, 1232-1239.

10. Park, J.-H., Vincent, D., \& Hastings-Tolsma, M. (2007). Disparity in prenatal care among women of colour in the USA. Midwifery, 23, 28-37.

11. Ny, P., Dykes, A. K., Molin, J., \& Dejin-Karlsson, E. (2007). Utilisation of antenatal care by country of birth in a multi-ethnic population: A four-year community-based study in Malmo, Sweden. Acta Obstetricia et Gynecologica Scandinavica, 86(7), 805-813.

12. Jeong-Hwang, J. H., Vincent, D., \& Hastings-Tolsma, M. (2007). Disparity in prenatal care among women of colour in the USA. Midwifery, 23, 28-37.

13. Rowe, R. E., Magee, H., Quigley, M. A., Heron, P., Askham, J., \& Brocklehurst, P. (2008). Social and ethnic differences in attendance for antenatal care in England. Public Health, 122, 1363-1372.

14. Villar, J., \& Bergsjo, P. (1997). Scientific basis for the content of routine antenatal care. I. Philosophy, recent studies, and power to eliminate or alleviate adverse maternal outcomes. Acta Obstetricia et Gynecologica Scandinavica, 76(1), 1-14.

15. Foets, M., Schuster, J., \& Stronks, K. (Eds.). (2007). Gezondheids(zorg) onderzoek onder allochtone bevolkingsgroepen. Een praktische introductie. Amsterdam: Aksant.

16. McCaw-Binns, A., La Grenade, J., \& Ashley, D. (1995). Underusers of antenatal care: A comparison of non-attenders and late attenders for antenatal care, with early attenders. Social Science and Medicine, 40(7), 1003-1012.

17. Blondel, B., \& Marshall, B. (1996). Women with little or no prenatal care during pregnancy. Results of a study of twenty departments. Journal de Gynécologie, Obstétrique et Biologie de la Reproduction (Paris), 25(7), 729-736.

18. Melnikow, J., \& Alemagno, S. (1993). Adequacy of prenatal care among inner-city women. Journal of Family Practice, 37(6), $575-582$.

19. Delgado-Rodríguez, M., Gómez-Olmedo, M., Bueno-Cavanillas, A., \& Gálvez-Vargas, R. (1997). Unplanned pregnancy as a major determinant in inadequate use of prenatal care. Preventive Medicine, 26, 834-838.

20. Roberts, R. O., Yawn, B. P., Wickes, S. L., et al. (1998). Barriers to prenatal care: Factors associated with late initiation of care in a 
middle class Midwestern community. Journal of Family Practice, 47(1), 53-61.

21. Braveman, P., Marchi, K., Egerter, S., Pearl, M., \& Neuhaus, J. (2000). Barriersto timely insurance: The importance of prepregnancy factors. Obstetrics, Gynecology, 95(6(Part 1)), 874-880.

22. Delvaux, T., Buekens, P., Godin, I., \& Boutsen, M. (2001). Barriers to prenatal care in Europe. American Journal of Preventive Medicine, 21(1), 52-59.

23. Chandler, D. (2002). Late entry into prenatal care in a rural setting. Journal of Midwifery Women's Health, 47(1), 28-34.

24. Cano-Serral, G., Rodriguez-Sanz, M., Borrell, C., Perez Mdel, M., \& Salvador, J. (2006). Socioeconomic inequalities in the provision and uptake of prenatal care. Gaceta Sanitaria, 20(1), 25-30.

25. Blondel, B., \& Marshall, B. (1998). Poor antenatal care in 20 French districts: Risk factors and pregnancy outcome. Journal of Epidemiology and Community Health, 52, 501-506.

26. Nothnagle, M., Marchi, K., \& Egerter, S. (2000). Risk factors for late or no prenatal care following Medicaid expansions in California. Maternal and Child Health Journal, 4(4), 251259.

27. D'Ascoli, P. T., Alexander, G. R., Petersen, D. J., et al. (1997). Parental factors influencing patterns of prenatal care utilization. Journal of Perinatology, 17, 283-287.

28. Campbell, J. D., Mitchell, P., Stanford, J. B., \& Ewigman, B. G. (1995). Validating a model developed to predict prenatal utilization. Journal of Family Practice, 41(5), 457-464.

29. Hulsey, T. M. (2001). Association between early prenatal care and mother's intention of and desire for the pregnancy. $J$ Ostetricia Gynecologic, and Neonatal Nursing, 30, 275-282.

30. Andersen, R. M. (1995). Revisiting the behavioral model and access to medical care: Does it matter? Journal of Health and Social Behavior, 36(1), 1-10.

31. LaVeist, T. A., Keith, V. M., \& Gutierrez, M. L. (1995). Blackwhite differences in prenatal care utilization: An assessment of predisposing and enabling factors. Health Services Research, $30(1), 43-58$.
32. Anum, E. A., Retchin, S. M., \& Strauss, J. F. (2010). Medicaid and preterm birth and low birth weight: The last two decades. Journal of Women's Health, 19(3), 1-9.

33. Bais, J. M. J., \& Pel, M. (2006). The basis of the Dutch obstetric system: Risk selection. European Clinics in Obstetrics and Gynaecology, 2(4), 209-212.

34. http://www.nivel.nl/oc2/page.asp?PageID=10447\&path=/Startpunt/ Subsites/HOME\%20beroepen\%20in\%20de\%20zorg/Top/Aanvraag/ Spreidingskaarten/Statische\%20kaarten/Verloskundigen/Dichtheid\% 20naar\%20ROS-regio.

35. Jaddoe, V. W. V., Mackenbach, J. P., Moll, H. A., Steegers, E. A. P., Tiemeier, H., Verhulst, F. C., et al. (2006). The Generation R study: Design and cohort profile. European Journal of Epidemiology, 21, 475-484.

36. Jaddoe, V. W. V., van Duijn, C. M., van der Heijden, A. J., Mackenbach, J. P., Moll, H. A., Steegers, E. A. P., et al. (2008). The Generation R study: design and cohort update until the age of 4 years. European Journal of Epidemiology, 23, 801-811.

37. Aalders, M. (2001). Classification of the population with a foreign background in the Netherlands. Statistics Netherlands (accessed at 29-05-2007 www.cbs.nl).

38. www.nvog-documenten.nl/index.php?pagina=/richtlijn/pagina. php\&fSelectTG_62=75\&fSelectedSub=62\&fSelectedParent $=75$; $1-1-2006$.

39. Korenbrot, C. C., Steinberg, A., Bender, C., \& Newberry, S. (2002). Preconception care: A systematic review. Maternal and Child Health Journal, 6(2), 75-88.

40. de Weerd, S., \& Steegers, E. A. P. (2002). The past and present practices and continuing controversies of preconception care. Community Genet, 5, 50-60.

41. Marshall, H. C., Alexander-Young, M., \& Burnet, D. L. (2009). Health care Quality-improvement appoaches to reducing child health disparities. Pediatrics, 124, S224-S236.

42. Choté, A. A., de Groot, C. J. M., Bruijnzeels, M. A., Redekop, K., Jaddoe, V. W. V., Hofman, A., et al. (2009). Ethnic differences in antenatal care use in a large multi-ethnic urban population in the Netherlands. Midwifery. doi:10.1016/j.midw.2009.07.008. 